\title{
Current concepts in plasticity and nerve transfers: relationship between surgical techniques and outcomes
}

\author{
Mariano Socolovsky, MD, PhD, ${ }^{1}$ Martijn Malessy, MD, PhD, ${ }^{2}$ Dan Lopez, MD, ${ }^{3}$ \\ Fernando Guedes, MD, PhD, ${ }^{4}$ and Leandro Flores, MD, PhD ${ }^{5}$

\begin{abstract}
${ }^{1}$ Peripheral Nerve and Plexus Surgery Unit, University of Buenos Aires School of Medicine, Buenos Aires, Argentina; 2Department of Neurosurgery, University of Leiden Medical Center, Leiden, The Netherlands; ${ }^{3}$ Department of Neurosurgery, Hospital Juarez de México, México City, México; ${ }^{4}$ Department of Neurosurgery, Hospital Universitário Gaffré e Guinle, Federal University of Rio de Janeiro, Rio de Janeiro; and ${ }^{5}$ Department of Neurosurgery, Hospital das Forças Armadas, Brasília, Brazil
\end{abstract}

OBJECTIVE Neuroplasticity is analyzed in this article as the capacity of the CNS to adapt to external and internal stimuli. It is being increasingly recognized as an important factor for the successful outcome of nerve transfers. Better-known factors are the number of axons that cross the coaptation site, the time interval between trauma and repair, and age. Neuroplasticity is mediated initially by synaptic and neurotransmitter changes. Over time, the activation of previously existing but lowly active connections in the brain cortex contributes further. Dendritic sprouting and axonal elongation might also take place but are less likely to be prominent.

METHODS The authors reviewed different factors that play roles in neuroplasticity and functional regeneration after specific nerve transfers.

RESULTS The authors found that these different factors include, among others, the distance between cortical areas of the donor and receptor neurons, the presence versus absence of preexisting lowly active interneuronal connections, gross versus fine movement restoration, rehabilitation, brain trauma, and age.

CONCLUSIONS The potential for plasticity should be taken into consideration by surgeons when planning surgical strategy and postoperative rehabilitation, because its influence on results cannot be denied.

https://thejns.org/doi/abs/10.3171/2016.12.FOCUS16431

KEY WORDS brain plasticity; neuroplasticity; brachial plexus surgery; nerve transfer

$\mathrm{T}$ HE underlying goals of brain and spinal cord surgery are generally to 1) decompress nervous tissue (i.e., to treat trauma, tumors, degenerative processes, and infections), 2) maintain or restore circulation (vascular surgery), and 3) resect or otherwise stimulate areas that interfere with normal function (functional neurosurgery). In contrast to brain and spinal cord injury, damaged nerves can be repaired surgically based on axons' capacity to grow after being sectioned. The restoration of neurological function after these procedures is primarily attributable to the direct effects of surgery, often times aided by the process of neuroplasticity. This term refers to the CNS's ability to reorganize and adapt to internal changes or environmental stimuli and thereby optimize functional outcome.
The term "brain plasticity," although popular, limits such plasticity to the brain while ignoring other changes that occur in the spinal cord.

Plasticity is not linked only to pathological scenarios. For example, learning new repetitive motor skills is also associated with neuroplasticity. In a study of primates specifically trained to use a single finger to perform a specific task, the researchers documented expansion of the motor cortical representation of that finger and diminution of the motor cortical representation of the remaining fingers of the same hand. Motor skill training enhances plastic changes in the CNS, something that does not happen when enhanced strength is the only goal of training. ${ }^{31}$

Neurosurgeons require some level of understanding of

ABBREVIATIONS BPI = brachial plexus injury; ICN = intercostal nerve; $\mathrm{MCN}=$ musculocutaneous nerve; $\mathrm{NBPP}=$ neonatal brachial plexus palsy . SUBMITTED October 23, 2016. ACCEPTED December 13, 2016. INCLUDE WHEN CITING DOI: 10.3171/2016.12.FOCUS16431. 
neuroplasticity to plan their surgeries. For instance, modern techniques for brain tumor resection in eloquent areas include the precise localization of each function via brain mapping. Eloquent zones must be preserved during surgery with the patient awake. Moreover, if an eloquent area is affected by a slow-growing tumor, experienced neurosurgeons generally avoid resecting that part of the tumor. It is well established that tumor progression in the years thereafter will diminish the functional importance of the area significantly, which will enable a safer resection of the expanded tumor later. ${ }^{12,58}$

Not all plasticity-related changes should be automatically considered beneficial. For instance, both deafferentation pain after severe brachial plexus injury (BPI) with root avulsions and phantom limb pain after an amputation are linked to maladaptive processes mediated by plasticity. ${ }^{8,39,53}$ These pain stages are linked to the creation of a "black hole" in brain sensory zones that no longer receive afferent information.

Severe peripheral nerve lesions and severe BPI result in a complete loss of afferent and efferent input to the CNS, which thereby produces a number of important changes in the CNS. Some of these changes occur immediately after the injury, ${ }^{38,66}$ and many of them expand beyond the sensorimotor cortex. ${ }^{15,37}$ The trigger for brain reorganization is deafferentation. In fact, much of what we know about plasticity stems from studies conducted in amputees, in whom the original hand motor cortex is "invaded" by facial zones of the cortex., ${ }^{2,14,30,65}$ In patients who wear a myoelectric hand prosthesis, the original hand cortex is spared. ${ }^{47} \mathrm{Simi}-$ larly, after certain nerve lesions, invasion of the deafferentiated zone by adjacent areas of the cortex related to nerves that remained intact typically occurs. ${ }^{53}$ After nerve repair, most previously denervated areas again become active in motor control and perception. The cortical maps, however, are disturbed because of axonal misrouting. ${ }^{40}$

The main objective of this article is to link the outcome of nerve transfers, applied predominantly in surgery for the treatment of BPI, in view of our current understanding of brain plasticity.

\section{Intercostal or Phrenic Nerve Transfer to the Musculocutaneous Nerve for Elbow Flexion}

Brain plasticity after intercostal-to-musculocutaneous nerve (ICN-MCN) transfer in surgery on the brachial plexus has been studied the most extensively. At the beginning of recovery, patients who have undergone this nerve transfer generally exhibit involuntary contraction of the biceps that is linked to breathing. After a short period of time, patients become aware that they can contract their biceps, but only by sustained inspiration or expiration. However, contraction (and the maintenance of elbow flexion) ultimately becomes independent of respiration. Flexion then can be maintained while the patient breathes normally. Complete independence between the 2 functions, however, is never actually achieved..$^{43}$

In plasticity studies, researchers have found that after ICN-MCN transfers, flexion is initially controlled by the sagittal region of the primary motor cortex..$^{43}$ This area is related to the intercostal muscles active in respiration (Fig.
1 left). After a few months, however, the original more laterally located area for voluntary biceps control becomes involved (Fig. 1 right). This shift in cortical activity from medial to lateral is most likely based on the activation of a preexisting interneuronal network with low-activity connections between the 2 involved cortical areas (Fig. 2).

Intercostal muscles contract simultaneously with the biceps when, for instance, a heavy object is lifted. This movement, after all, requires not only biceps contraction but also, although less obvious, stabilization of the thorax and torso posture.

From these studies it was concluded that to achieve successful voluntary control after nerve transfer, the donor and acceptor must have some connection between the 2 motor areas (i.e., horizontal intrinsic connections) before transfer. ${ }^{22}$ These central connections are activated by peripheral nerve transfers, which thereby induce plastic changes in the cortex.

Similar changes from breathing-related control to voluntary flexion independent from breathing can be observed after a phrenic nerve-MCN transfer, with which the same clinical progression (starting with respirationcontrolled arm movement, followed by voluntary control of elbow flexion) is seen. The reported results of phrenic nerve-MCN transfers are comparable to, and in some cases better than, those of ICN-MCN transfers, ${ }^{36,56}$ which might have several explanations, including the greater number of axons that the phrenic nerve has relative to ICNs (Fig. 3).

\section{Hypoglossal Nerve as Donor to the MCN or Facial Nerve}

Good biceps muscle strength can be obtained with a hypoglossal nerve-MCN transfer..$^{42}$ The functional outcome, however, is poor, because independent voluntary control over the reinnervated muscle is not restored. To control the biceps muscle to flex the elbow, the tongue has to be pushed against the hard palate. As soon as the tongue is relaxed, the biceps muscle also relaxes. Talking or chewing evokes involuntary biceps contractions, which cause the arm to move involuntarily. In contrast, good results (House-Brackmann Grade III $^{28}$ ) can be expected after a hypoglossal nerve-facial nerve transfer. ${ }^{24,26,49,57}$ One possible explanation for this discrepancy is that no connection between elbow flexion and the tongue cortical area exists (Fig. 4), whereas good horizontal connections between the tongue and the face area do exist (Fig. 5).

However, a final House-Brackmann grade of III after a hypoglossal nerve-facial nerve transfer implies good symmetry at rest and normal talking. If facial emotional movements (e.g., crying or laughing) are involved, asymmetry reappears, which is probably because no horizontal connections between emotion-controlled movements (which originate from different zones of the brain) and the hypoglossal cortex exist. In this case, as in many others, complete functional adaptation mediated by plastic changes has its limits.

\section{Contralateral C-7 Transfer}

The contralateral C-7 transfer technique can be used 


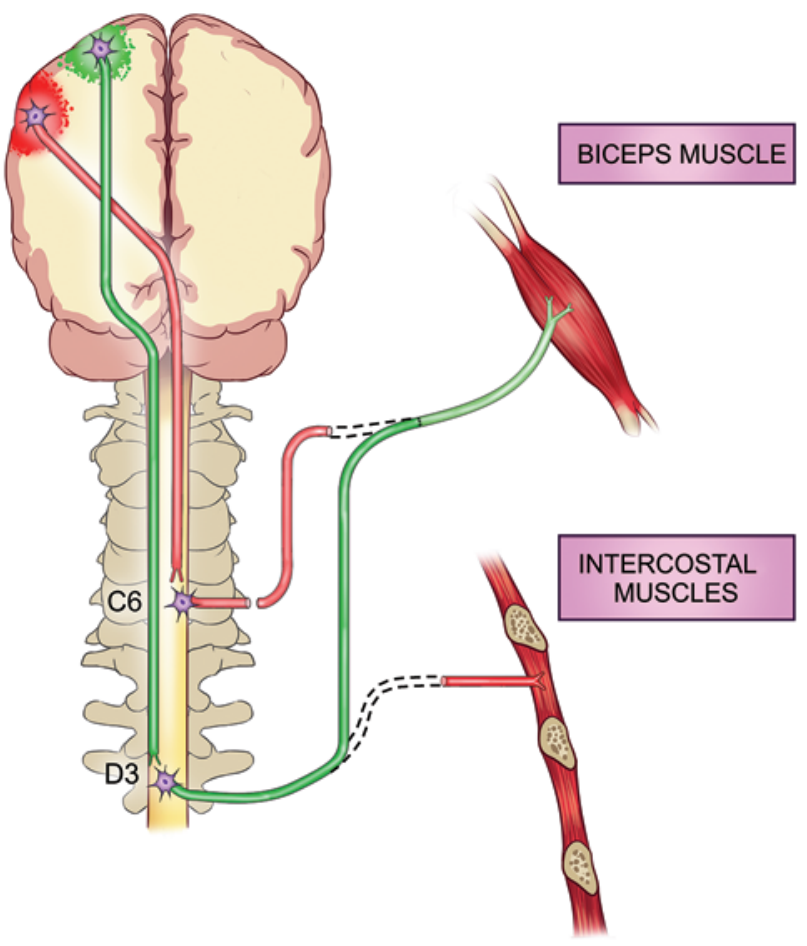

Early phase

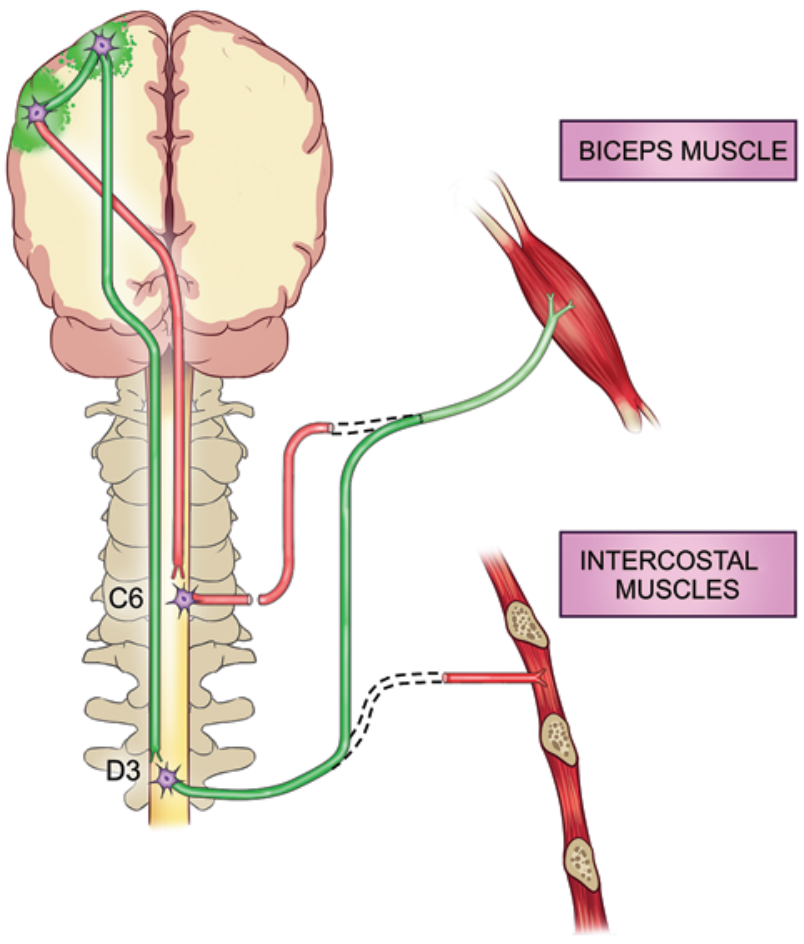

Late phase

FIG. 1. Neuroplasticity after an ICN-MCN transfer for brachial plexus traction injury with root avulsions. The original neural pathway for elbow flexion from the cortex to the cervical motor neuron pool via C-6 to the MCN, which was injured during the trauma, is shown in red. The newly restored connection after transfer of ICNs via the motor neuron pool at T-3 is shown in green. In the early phase of recovery (left), biceps contraction is possible by sustained inspiration or expiration. These movements are mediated by the original ICN's primary motor cortex located in the midline. Some months later (in the late phase [right]), patients learn to contract their biceps and thereby flex the elbow independently of respiration as if normal. Cortical activation is located in the laterally located original biceps' primary motor cortex area; note the newly reactivated connection between the 2 cortexes (green arch). Copyright Mariano Socolovsky. Published with permission.

to treat severe BPI with root avulsions. In this technique, the spinal nerve C-7 from the healthy arm is transferred partially or completely to a target nerve in the affected upper limb. The literature on contralateral C-7 transfers was reviewed recently, ${ }^{63,64}$ and the results were not as excellent as originally believed. The major concern is that most patients never regain independent movement control. Indeed, to move the affected limb, they have to flex their healthy arm to initiate muscle contraction in the reinnervated limb.

A functional MRI study revealed that bilateral activation of the motor cortex occurs during movement of the reinnervated arm. ${ }^{4}$ The original motor area for flexion of the arm is still involved but in concert with the ipsilateral cortex, which normally is not the case (Fig. 6). This process is mediated by bilateral premotor and primary motor connections, which provides an explanation for the main drawback of this technique, namely, that very few patients regain motor control that is independent of their normal, unaffected side.

One case study ${ }^{11}$ is of particular interest with respect to interhemispheric connections. A woman who suffered an amputation of her right arm above the elbow and who also had complete avulsion of the left brachial plexus un- derwent reconstructive surgery. The right brachial plexus was connected to the left brachial plexus by interposing grafts, and she recovered several movements in her left arm. However, to effect these movements, she had to think about flexing her phantom right arm. It is interesting that on functional MRI, signals were detected bilaterally in the thalamus, caudate, insula, and sensorimotor cortex during any elbow-flexion task.

\section{Plasticity in Distal Nerve Transfers in Relation to Adjacency of Motor Areas}

The transfer of a nerve fascicle of the ulnar nerve to a biceps branch (the Oberlin procedure) was popularized in 1994. ${ }^{45}$ This technique changed brachial plexus surgery profoundly. First considered a "salvage procedure" for use when roots are avulsed and not available for grafting, the procedure has transformed over the years into a first-line procedure for biceps reinnervation in adults and is being increasingly used in children. ${ }^{44,54,59}$ One big reason for the popularity of the so-called Oberlin procedure is the high success rate of $90 \%$ or greater. One variation in the original technique, which increases the number of axons reaching the agonist target muscles (e.g., double transfers 


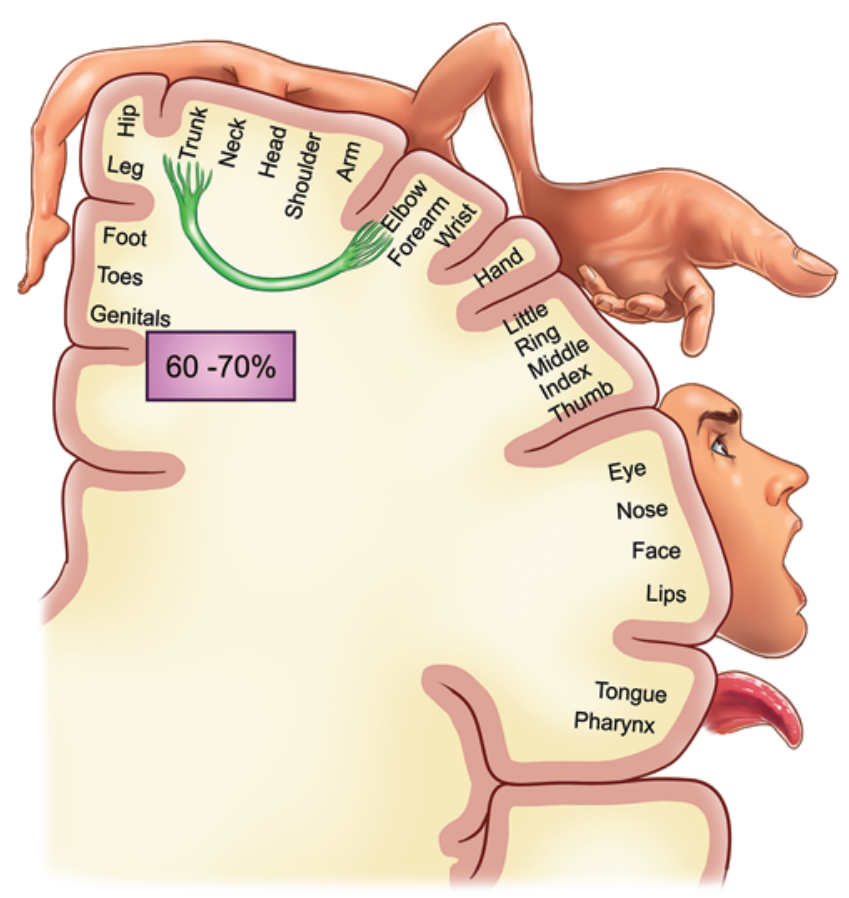

Martin Montalbetti

FIG. 2. As a result of peripheral ICN-MCN transfer, a central low-activity interneuronal network (green arch) between the intercostal and biceps primary motor areas becomes involved in flexion control because of plastic changes that take months to develop. The reported rate of success of this transfer has been highly variable in the literature; an average of $60 \%-70 \%$ of patients ultimately achieve a British Medical Research Council scale level of $\geq \mathrm{M} 3$ strength for elbow flexion. Artist: Martin Montalbetti. Copyright Mariano Socolovsky. Published with permission.

from ulnar to biceps and median to brachialis nerves) has generated even better results; between $95 \%$ and $99 \%$ of patients experience a good result. Other distal nerve transfers based on this concept (e.g., triceps branch-axillary nerve transfer [so-called Somsak procedure] ${ }^{33,62}$ and wrist and finger extension branch-triceps branch transfer ${ }^{18}$ ) have also been associated with very high success rates.

The success of Oberlin's nerve transfer is based on the short distance that the outgrowing axon has to cross. Because the transfer is performed distally, the distance to the target muscle is no more than a few centimeters, which explains why muscle reinnervation occurs much faster. Therefore, the deleterious effects of prolonged denervation are diminished dramatically. ${ }^{23}$ In addition, successful distal transfers illustrate the 2 core principles of neuroplasticity that determine good results: 1) the donor and acceptor cortical regions share the same motor control pathways and 2) previous connections between the 2 areas exist (Figs. 7 and 8). It can be speculated that not only the short distance to the target muscles but also the good conditions for plasticity explain the high rates of success of distal nerve transfers.

One patient who recently underwent the Oberlin procedure was compared with a control individual. The authors found that the areas and peaks of activation were quite similar. These findings provide additional support for the

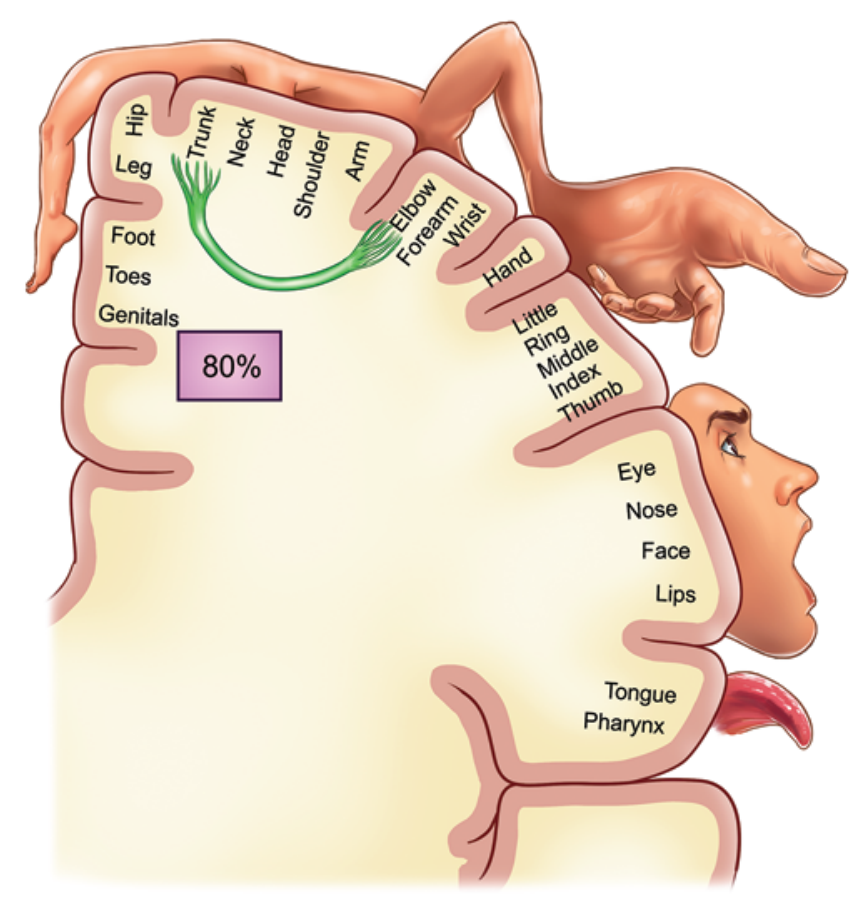

Martin Montalbettio

FIG. 3. Similar to what happens with ICN-MCN transfers, when the phrenic nerve is transferred, changes occur in the cortex, mediated by neuroplasticity. The green arch represents a preexisting connection between the phrenic and elbow motor cortex. The rate of success of this technique (from reported series) tends to be higher than that for ICN transfers (more than $80 \%$ of patients achieve $\geq$ M3-level biceps flexion). Despite this high rate of successful reinnervation, the technique is not widely accepted, primarily because of respiratory concerns. Artist: Martin Montalbetti. Copyright Mariano Socolovsky. Published with permission.

role of plasticity in attaining the excellent results that distal nerve transfers generally achieve. ${ }^{10}$

\section{Reinnervation of Hand Movement: Is It Just a Problem of Target Distance?}

The results of hand reinnervation after BPI in adults have been poor. The classic explanation is the long distance that axons have to elongate to reach their distal muscle targets. Although this distance is unquestionably a factor, additional issues regarding neuroplasticity in relation to hand reinnervation control should be considered..$^{37}$

First, shoulder or elbow movements, which are gross, respond better to reinnervation than finer hand movements. ${ }^{34,53}$ Distal nerve transfers undertaken to reinnervate the hand (which eliminate the deleterious effects of long distance) with pure motor targets (which diminish axonal misrouting or dispersion) yield acceptable results for hand- and finger-grasping tasks. However, intrinsic muscles recover poorly, and fine movements that the normal human hand is able to perform are not recovered.

Second, in examining the extent of cortical representation of the hand (and especially the thumb) in the motor cortex, it is easy to understand that a BPI that affects the $\mathrm{C}-7, \mathrm{C}-8$, and $\mathrm{T}-1$ roots produces extensive denerva- 


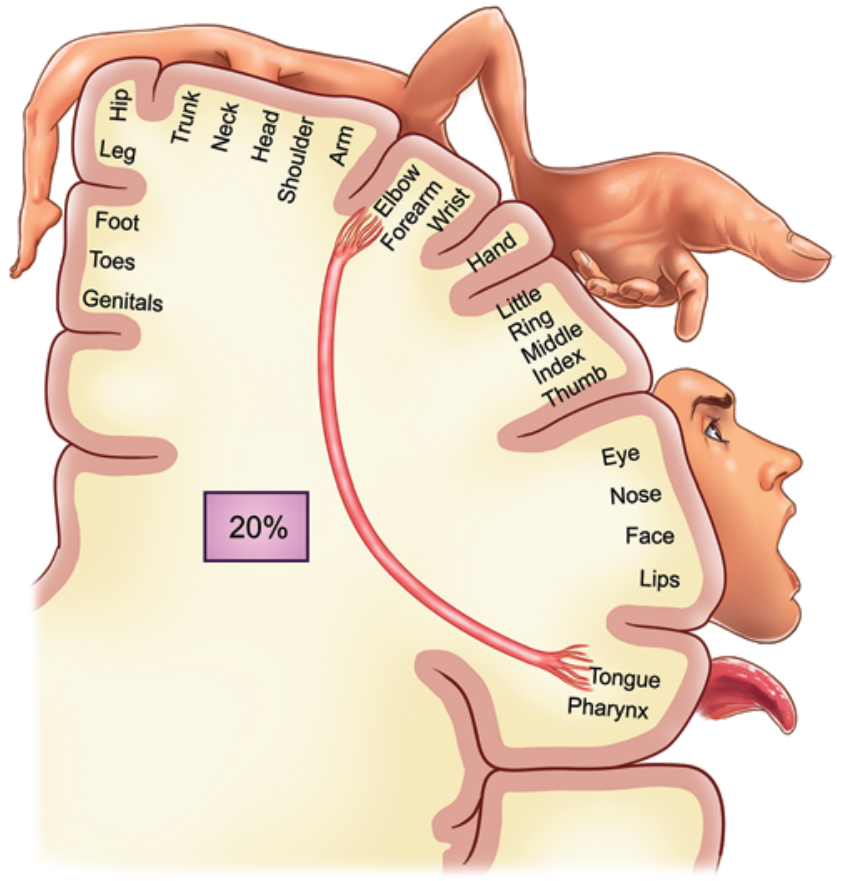

Martín Montalbettio

FIG. 4. Hypoglossal nerve-MCN transfer can result in good biceps contraction but only when the patient pushes his or her tongue against the hard palate. As soon as the tongue relaxes, the biceps also relaxes (e.g., chewing results in involuntary biceps contractions). The red arch represents the lack of a preexisting connection between the cortex of the donor nerve tongue area and the recipient MCN biceps cortical area. Functional control over elbow flexion is poor as a result of the lack of any preexisting connection. Artist: Martin Montalbetti. Copyright Mariano Socolovsky. Published with permission.

tion. It is unlikely that any surgical reinnervation will be adequately reparative (Fig. 9). The "black hole" that remains is so large because it is not possible at present to get enough axonal donors to fill it adequately.

Moreover, in both the published literature and our own experience, motor hand reinnervation does not produce good results in patients with complete brachial plexus palsy. Some isolated attempts at flexor reinnervation via phrenic nerve transfers, in special cases, yielded some recovery of finger flexion. However, the problem is not how forcefully the muscles move but how useful the movements are. Even with acceptable muscle contraction and finger flexion, such movement is not truly independent of breathing, as when innervating the elbow. Plastic changes in the cerebral cortex do not occur in these patients, because the connections between the hand and trunk are far from each other and the 2 areas do not share the same motor pathways (Fig. 10).

\section{Reinnervation of Sensation}

The intercostobrachialis nerve, a sensory nerve that supplies sensation to the skin of the thoracic wall and axilla, was used for transfer to the sensory component (lateral contribution) of the median nerve. ${ }^{21}$ A couple of years after the procedure, stimulating the median nerve territory

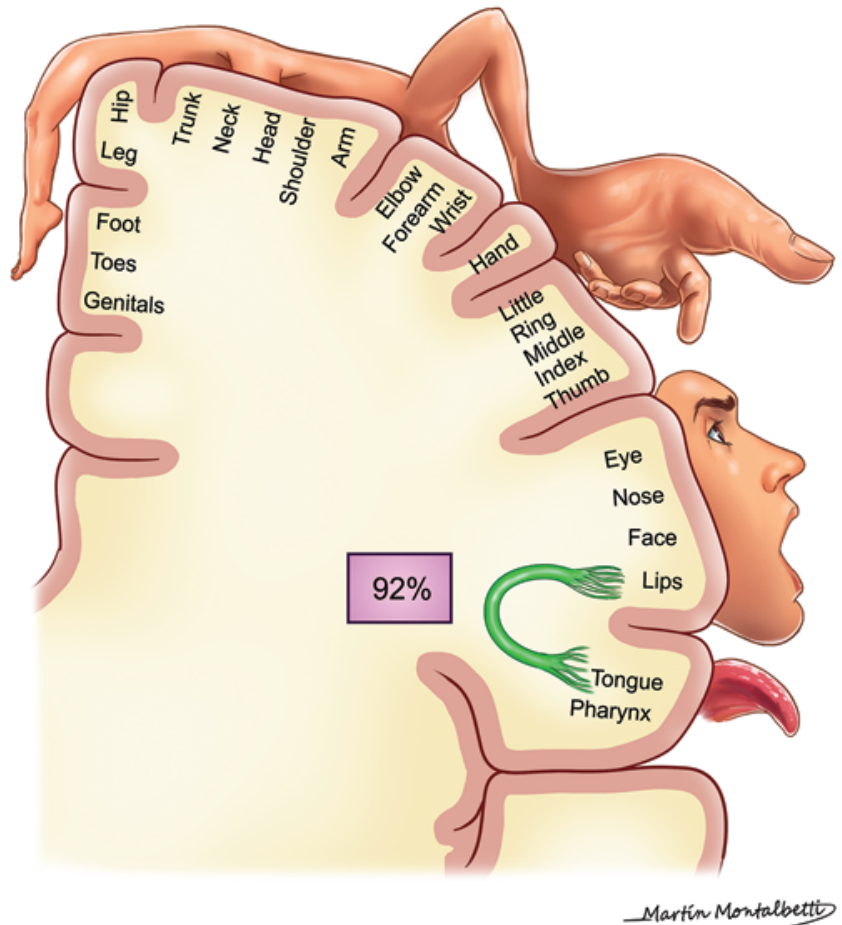

FIG. 5. The hypoglossal and facial nerve cortical areas are in close proximity. Most likely connections between the 2 areas exist in view of close interactions during certain tasks, such as chewing or eating, which might in part explain the high rate of success observed with hypoglossal nerve- or masseter nerve-facial nerve transfer techniques applied for facial palsies (green arch). Artist: Martin Montalbetti. Copyright Mariano Socolovsky. Published with permission.

of the injured hand was perceived by the patient but only in his axilla (L. Foroni, personal communication, 2016). This finding was predicted by one of the authors (M.M.) based on the following observation after ICN-MCN transfer. If the area of the lateral antebrachial cutaneous nerve is touched or stroked, patients locate sensation on the thoracic wall, even years after the ICN-MCN transfer. So, although voluntary motor control over the biceps is restored, it does not account for localization of sensation, which reveals that sensitive plasticity and motor plasticity do not follow the same pathways, as would be logical to presume. Even when a good result in terms of restoring protective sensation is attained, this example clearly reveals some of the limitations of neuroplasticity.

\section{Effects of Brain Trauma}

Contrary to humans and primates, rats were found to be unable to readapt function after a nerve transfer, even when the transfer was successful. ${ }^{6}$ Despite having electrophysiologically proven axonal continuity, rats cannot learn to move a certain target muscle after reinnervation. In all likelihood, the lack of effective brain plasticity in rats explains these findings. Can we link this knowledge to what happens in a severely injured human brain?

In fact, to our knowledge, the effect of traumatic brain damage on the success of peripheral nerve recovery has not been studied extensively in humans. It is our (M.S.) 


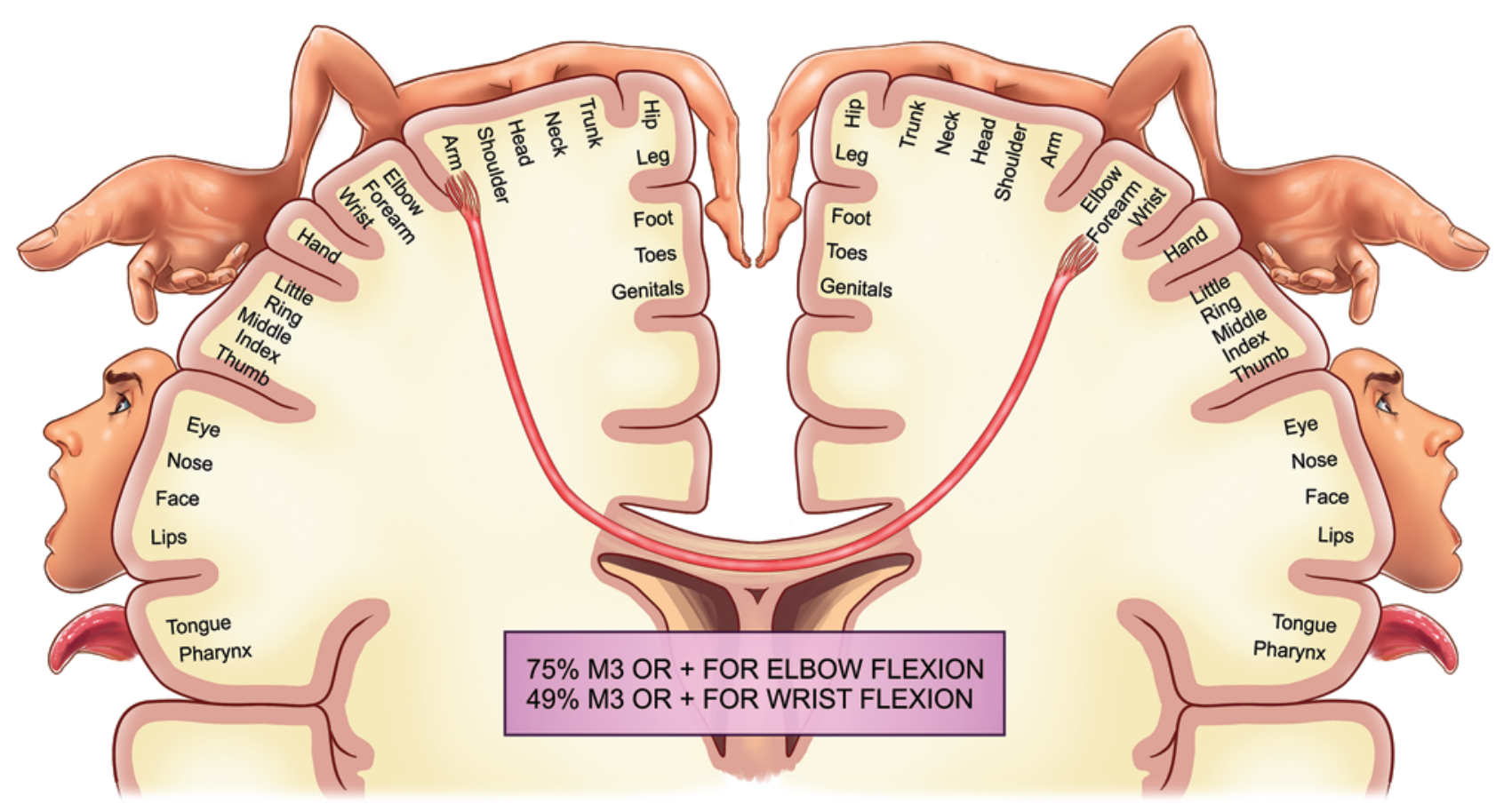

Martin Montalbetti

FIG. 6. Contralateral C-7 transfers involve complex changes mediated by cerebral plasticity. This process is mediated by bilateral premotor and primary motor connections and provides an explanation for the main drawback of this technique, that is, very few patients regain motor control that is independent of their normal, unaffected side. Indeed, to move the affected limb, they have to flex their healthy arm to initiate muscle contraction in the reinnervated limb. Artist: Martin Montalbetti. Copyright Mariano Socolovsky.

Published with permission.

clinical experience, however, that in patients with concomitant brain injury and BPI, the results of reconstructive brachial plexus surgery are worse than those in patients with isolated BPI, which might be a result of extensive injury to the white matter subcortical networks that are involved in brain plasticity (Fig. 11).

It is interesting to note that in a recently published report, it was shown that C-7 transfers promote locomotor recovery in rats even when they have a severely injured contralateral hemisphere. ${ }^{29}$ The corpus callosum, as the main connection between the 2 hemispheres at the cortical level, is the main pathway for this enhancement.

Precise knowledge about the effect of brain trauma on these mechanisms remains lacking. Until more is known, patients with concomitant brain injury and BPI should be considered cautiously as candidates for reconstructive brachial plexus surgery.

\section{Neonatal Brachial Plexus Palsy}

It has been demonstrated extensively that the results of nerve surgery to treat neonatal brachial plexus palsy (NBPP) are superior to those of surgery in adults with BPI because of the higher axonal regenerative capacity in infants. ${ }^{35,46}$ Even functional hand reinnervation can be obtained in patients with NBPP and is actually the first objective of reconstruction in those with complete palsy. The 2 main explanations for this success are that 1) the potential for axon growth is greater in young children, and
2) the distances from the repaired brachial plexus to the muscle targets are shorter.

Modern concepts of neuroplasticity can be superimposed on this existing knowledge. Although neuroplasticity is retained over one's entire lifetime, it can be hypothesized that a young brain has a greater capacity for remodeling. In fact, it was shown recently in infants with right NBPP that hand dominance is located in the right hemisphere, ${ }^{16}$ which is also their language-dominant hemisphere. $^{3}$

As mentioned earlier, however, not all plasticity should be viewed in a positive light. In infants, there exists a phenomenon that has been called "developmental apraxia," in which the muscles are weak and produce no effective movement of the limb as a result of early adverse plasticity associated with erroneous central motor programming. With neurophysiological and intraoperative stimulation, however, these same muscles exhibit good function and strength. ${ }^{9}$

Another difference between infants and adults is that infants do not seem to develop neuropathic pain or phantom limb pain syndromes, as seen in adults. ${ }^{27}$ This difference is probably attributable to the extensive reinnervation that occurs in the young, which is contrary to the maladaptive response linked to partial reinnervation that commonly occurs in older children and adults. ${ }^{1,5}$

Another interesting finding reported in the literature is that after nerve transection and repair the immature brain receives disorganized sensory input, just as happens in 


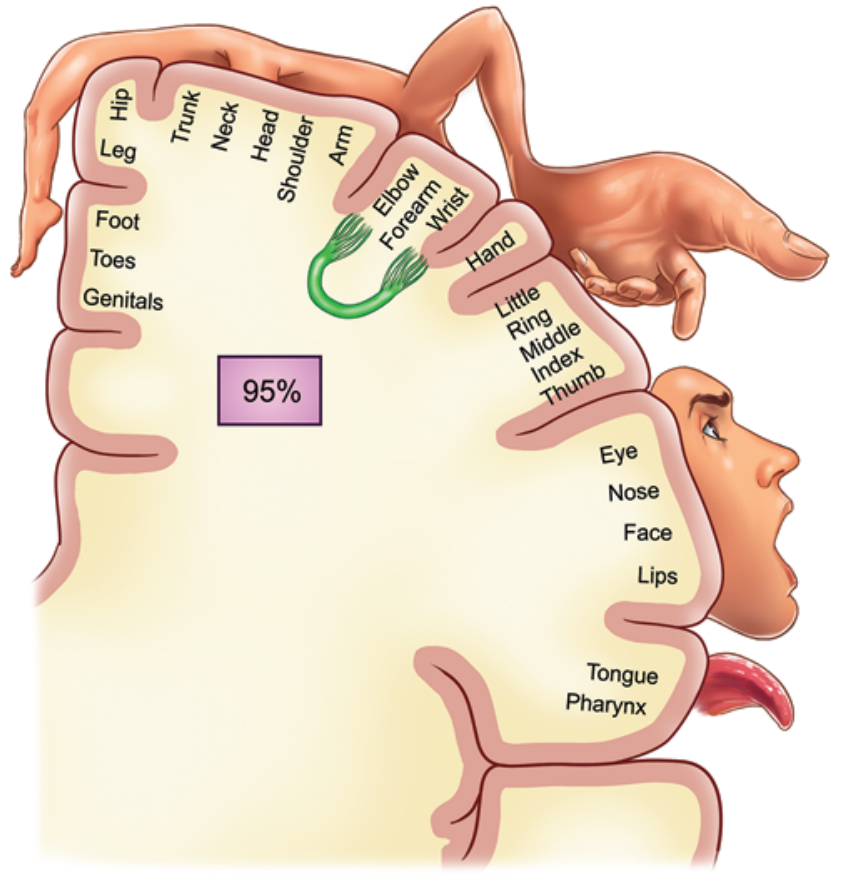

Martin Montalbetti

FIG. 7. Ulnar fascicle-MCN transfer (Oberlin technique) has a very high success rate (approximately 95\%). This high rate of success might be explained by 1) the presence of preexisting connections between forearm and wrist flexors on one side and biceps flexors on the other side, 2) the close proximity of the 2 involved cortices, and 3) similar motor pathways (green arch). Artist: Martin Montalbetti. Copyright Mariano Socolovsky. Published with permission.

adults. However, at least among immature monkeys, it has been demonstrated that such jumbled input can be reorganized to successfully create a new somatotopy, which leads to good sensory outcomes. ${ }^{17}$ This finding correlates well with the relatively good sensory response found in children after nerve reconstruction compared with that in adults. $^{13}$

Whatever the neurobiological background, these examples show the likelihood that neuroplasticity potential is more prominent after NBPP and might account partially for the good results obtained.

\section{The Problem of Combined Agonist and Antagonist Muscle Innervation}

Modern concepts of plasticity must be considered when performing simultaneous agonist and antagonist muscle reinnervation during surgery on the brachial plexus.

For instance, in a small series reported by Zheng et al. ${ }^{67}$ simultaneous phrenic nerve transfer for elbow flexion and ICN transfer for elbow extension yielded very poor results for elbow extension but good results for elbow flexion. Because both the phrenic nerve and ICN are activated during inspiration, they could be considered agonistic muscles. The predominance of elbow flexion over extension in this series might be explained by the phrenic nerve being a more effective donor because it has more axons than do

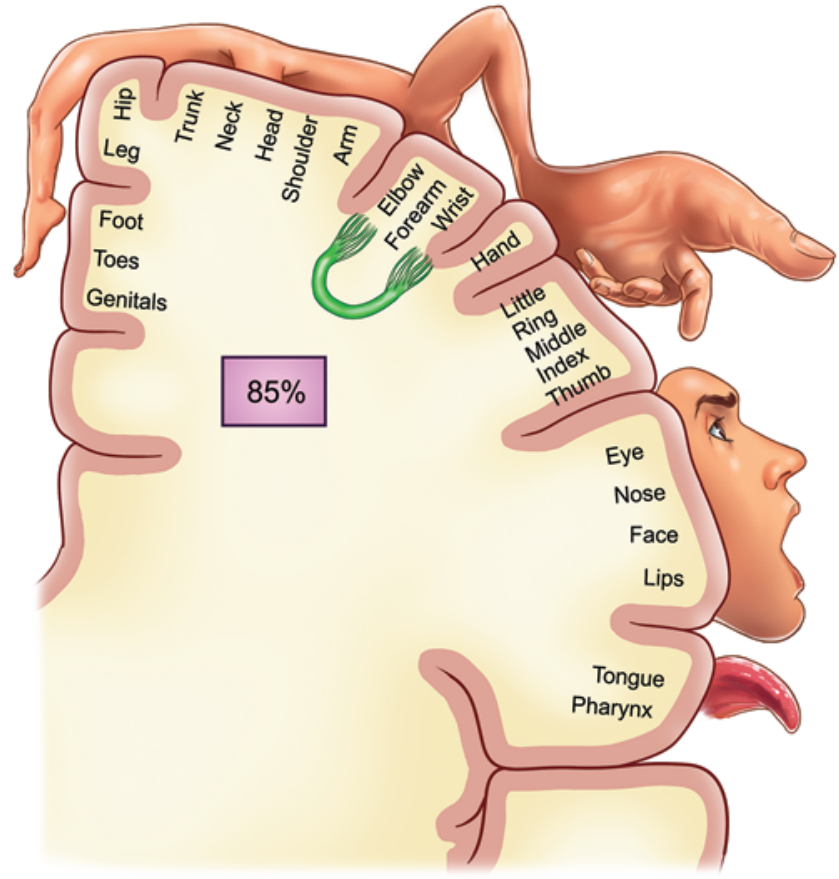

Martín Montalbetti

FIG. 8. For finger and wrist extensors-triceps branch nerve transfer, the Oberlin technique principles can be applied to explain the high success rate $(85 \%)$ (green arch). Artist: Martin Montalbetti. Copyright Mariano Socolovsky. Published with permission.

ICNs. It is assumed that the first muscle that is reinnervated (in this case, the biceps) initiates a cascade of brain reorganization, frustrating the successful regain of control over the antagonistic triceps. It is not known what would happen if donors were reversed; would the results for the triceps exceed those for the biceps?

In contrast with the results of Zheng et al., ${ }^{67}$ good elbow reinnervation using the phrenic nerve was obtained in a recent serie ${ }^{20}$ in which elbow extension also was attained successfully via a completely different donor (i.e., C-5 or C-6).

Another interesting finding that shows how impossible it is for the brain to innervate agonist and antagonist muscles simultaneously and successfully with the same donor can be found in a series report by Bertelli and Ghizoni.? They grafted antagonistic targets of the brachial plexus using either 1 or 2 roots. Among the 12 patients in whom they identified only 1 graft-eligible root, satisfactory elbow flexion was obtained in 10 patients. Simultaneous elbow extension did not recover. In 1 patient of the same group who also had only 1 graft-eligible root, the surgery resulted in good elbow extension, but the biceps remained weak and severe cocontractions were observed. In contrast, among 9 patients with 2 graft-eligible roots, 1 directed toward the biceps and the other toward the triceps (among other targets), successful reinnervation of both muscles was achieved in 4 of them.

In a recent article, Wang et al. ${ }^{61}$ described a small series of phrenic nerve transfers to the posterior division of the lower trunk in a very young patient population (mean age 


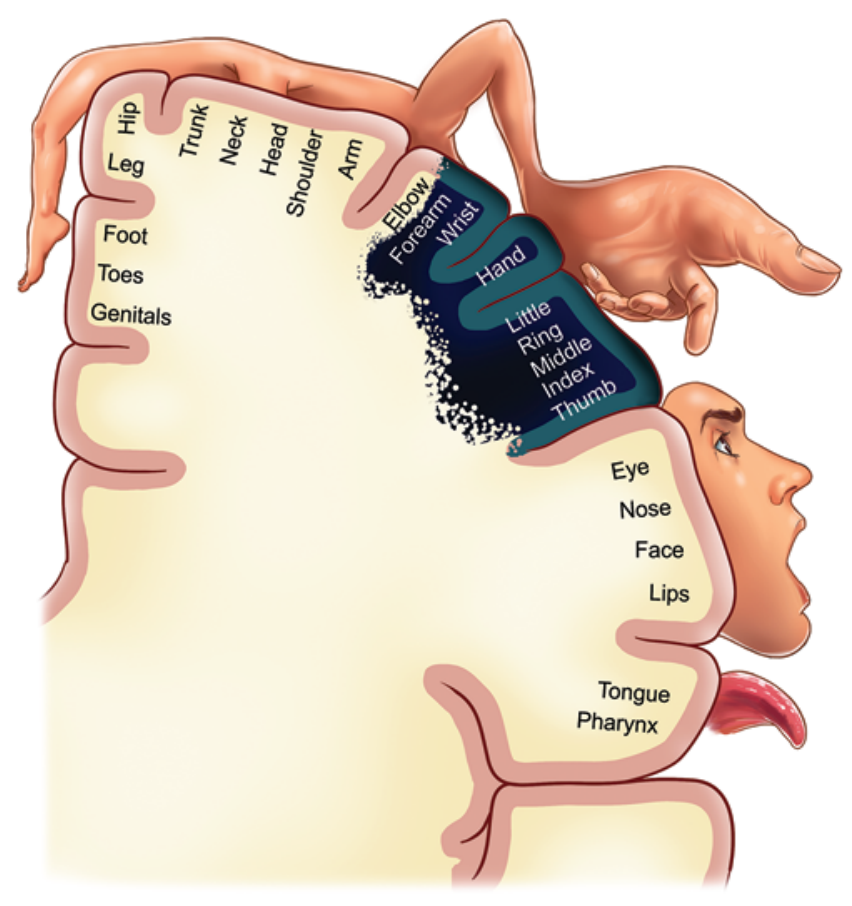

Martin Montalbettio

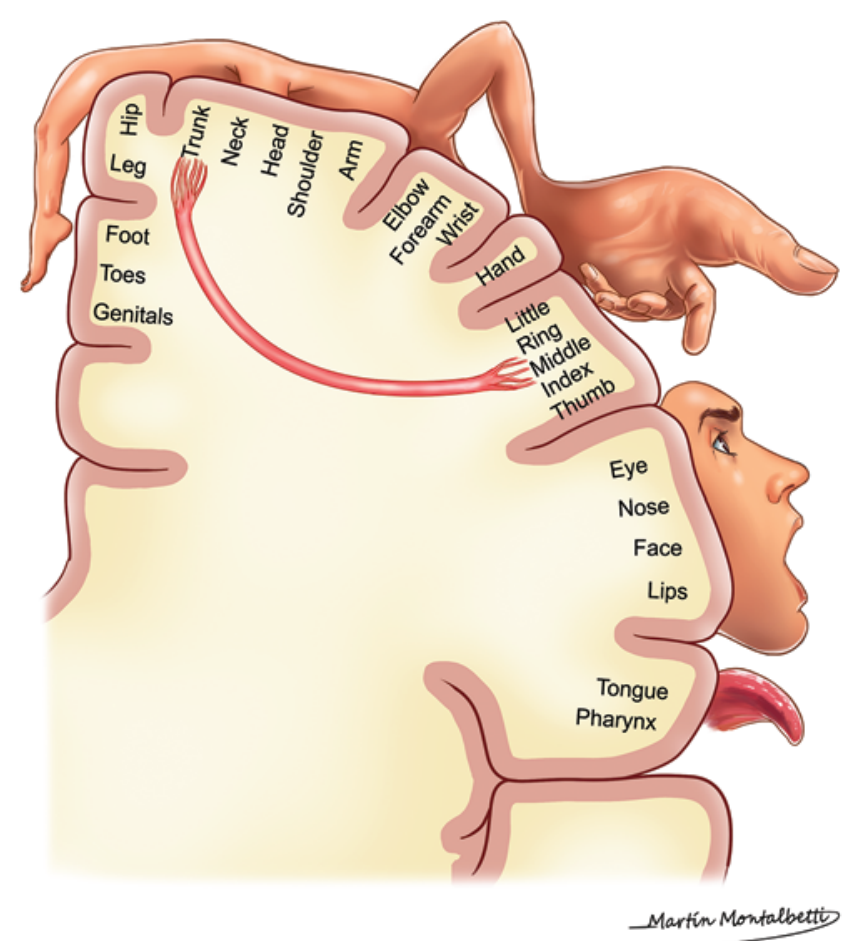

FIG. 10. Motor hand reinnervation does not produce good results in patients with complete brachial plexus palsy. However, some isolated attempts at long-finger flexor reinnervation via phrenic nerve transfers, in special cases, have yielded some recovery of finger flexion. The movement, however, was not independent of respiration. Plastic changes do not take place in such patients, because connections between the hand and trunk are too separated and the 2 areas do not share the same motor pathways. Some other factors might contribute to these poor results, including the extent of original denervation and the existence of fine movements in the recipient zone, which generally do not respond well to reinnervation. Artist: Martin Montalbetti. Copyright Mariano Socolovsky. Published with permission.

tagonistic distal radial nerve branches and likewise used radial nerve branches to innervate antagonist median nerve-dependent muscles. These authors emphasized the importance of early rehabilitation for reaching a good outcome and the fact that they needed, on some occasions, to combine these procedures with a tendon transfer to obtain better functional results.

In contrast, in an analysis of the results of agonist muscle reinnervation after antagonist nerve transfer in the lower limbs (i.e., tibial branch-deep peroneal nerve transfer), the results of both experimental ${ }^{32}$ and clinica ${ }^{19}$ studies of functional foot-drop recovery were poor. We could theorize that a difference in neuroplasticity between the upper and lower limbs, induced by differences in cortical representations or subcortical/spinal circuit connections, exists. Nevertheless, more studies in this field have to be done before drawing final conclusions.

\section{Role of Rehabilitation}

Several published reports effectively support what has been believed for a long time: that rehabilitation after the surgical repair of BPI is very important in determining the final outcome..$^{55,56}$ 


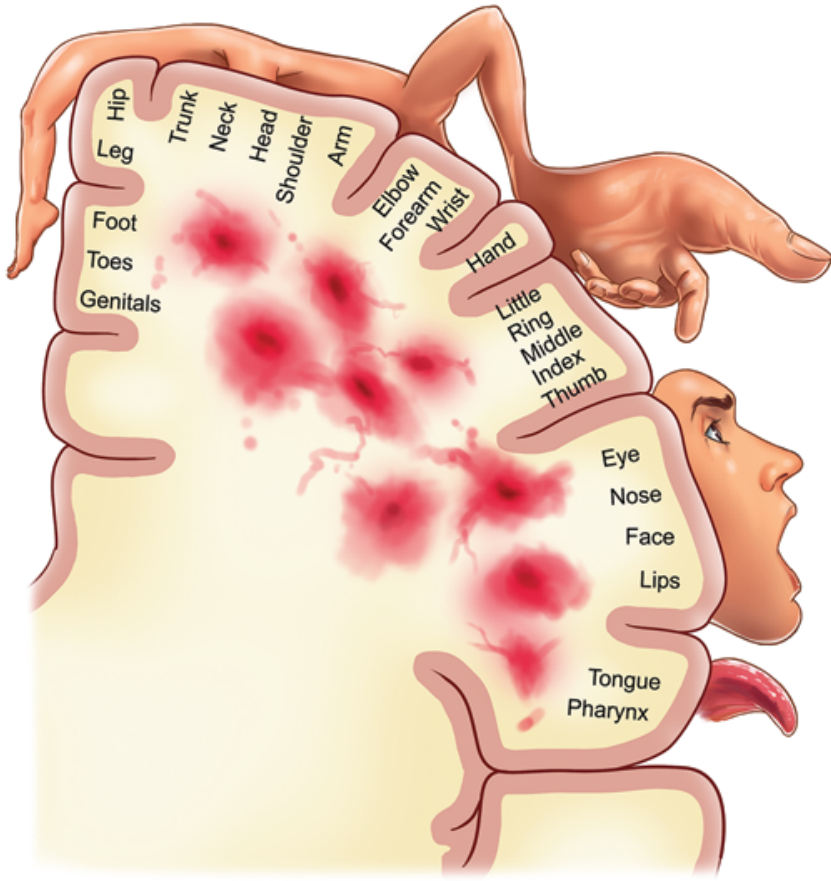

Martin Montalbettit

FIG. 11. Results of nerve surgery in patients with both a brain injury and $\mathrm{BPI}$ could be worse than those in patients with only isolated BPI, which might be a result of extensive damage to the white matter subcortical networks that are involved in brain plasticity. However, this hypothesis has not been confirmed empirically. Artist: Martin Montalbetti. Copyright Mariano Socolovsky. Published with permission.

Here again an understanding of neuroplasticity influences therapy for BPI, in this case the specific forms of rehabilitation used. Therapies such as sensory reeducation, constraint-induced movement therapy, and exercise ${ }^{50}$ target postoperative rehabilitation using this knowledge.

Sensory recovery may not only be important in restoring protective tactile sensation, it may also play a role in the modulation of neuroplasticity during motor learning. It has been hypothesized, for example, that sensory input might impede aberrant plasticity and ultimately enhance the functional motor result. ${ }^{2}$

Anesthetizing the forearm also was shown to yield better motor and sensory results in denervated hands. ${ }^{50}$ It is interesting to note that a hypothesis that might explain this result could be called "controlled plasticity," meaning that anesthetizing the adjacent cortex might impede any invasion of the really deafferentiated cortex by nondeafferentiated cortex, as normally occurs during brain plasticity.

Therefore, as stated by Anastakis et al., ${ }^{2}$ the keys to successful rehabilitation after a nerve transfer include 1) preoperative training that details the movements required to activate the nerve transfers, 2) repetition to reinforce plasticity, especially during the early stages of motor relearning, and 3) a minimum-length training program of 2 years, with strengthening exercises starting after initial motor movement is observed.

It has been demonstrated that exercise and electrical stimulation both promote peripheral nerve regeneration, ${ }^{25}$ and an explanation for this finding might be that both of them enhance neuroplasticity.

\section{Conclusions}

Neuroplasticity is increasingly being recognized as one of the factors that determines the success or failure of certain nerve-transfer procedures, contributing to the effects of long-recognized influential factors such as the duration of time between the initial trauma and reparative surgery and the extent of the primary damage. Investigators who intend to develop new transfers in nerve surgery should keep in mind the principles of neuroplasticity, because the capacity of the CNS to reorganize is limited. Above all, surgical strategies and postoperative rehabilitation programs should be guided by modern concepts in neuroplasticity, because we all strive to obtain better results for our patients.

\section{References}

1. Anand P, Birch R: Restoration of sensory function and lack of long-term chronic pain syndromes after brachial plexus injury in human neonates. Brain 125:113-122, 2002

2. Anastakis DJ, Malessy MJ, Chen R, Davis KD, Mikulis D: Cortical plasticity following nerve transfer in the upper extremity. Hand Clin 24:425-444, vi-vii, 2008

3. Auer T, Pinter S, Kovacs N, Kalmar Z, Nagy F, Horvath RA, et al: Does obstetric brachial plexus injury influence speech dominance? Ann Neurol 65:57-66, 2009

4. Beaulieu JY, Blustajn J, Teboul F, Baud P, De Schonen S, Thiebaud JB, et al: Cerebral plasticity in crossed C7 grafts of the brachial plexus: an fMRI study. Microsurgery 26:303310, 2006

5. Berman JS, Birch R, Anand P: Pain following human brachial plexus injury with spinal cord root avulsion and the effect of surgery. Pain 75:199-207, 1998

6. Bertelli JA, Ghizoni MF: Concepts of nerve regeneration and repair applied to brachial plexus reconstruction. Microsurgery 26:230-244, 2006

7. Bertelli JA, Ghizoni MF: Results of grafting the anterior and posterior divisions of the upper trunk in complete palsies of the brachial plexus. J Hand Surg Am 33:1529-1540, 2008

8. Blom SM, Pfister JP, Santello M, Senn W, Nevian T: Nerve injury-induced neuropathic pain causes disinhibition of the anterior cingulate cortex. J Neurosci 34:5754-5764, 2014

9. Brown T, Cupido C, Scarfone H, Pape K, Galea V, McComas A: Developmental apraxia arising from neonatal brachial plexus palsy. Neurology 55:24-30, 2000

10. de Sousa AC, Guedes-Corrêa JF: Post-Oberlin procedure cortical neuroplasticity in traumatic injury of the upper brachial plexus. Radiol Bras 49:201-202, 2016

11. Dimou S, Biggs M, Tonkin M, Hickie IB, Lagopoulos J: Motor cortex neuroplasticity following brachial plexus transfer. Front Hum Neurosci 7:500, 2013

12. Duffau H: A personal consecutive series of surgically treated 51 cases of insular WHO Grade II glioma: advances and limitations. J Neurosurg 110:696-708, 2009

13. Duteille F, Petry D, Poure L, Dautel G, Merle M: A comparative clinical and electromyographic study of median and ulnar nerve injuries at the wrist in children and adults. J Hand Surg [Br] 26:58-60, 2001

14. Elbert T, Flor H, Birbaumer N, Knecht S, Hampson S, Larbig W, et al: Extensive reorganization of the somatosensory cortex in adult humans after nervous system injury. Neuroreport 5:2593-2597, 1994

15. Feng JT, Liu HQ, Hua XY, Gu YD, Xu JG, Xu WD: Brain 
functional network abnormality extends beyond the sensorimotor network in brachial plexus injury patients. Brain Imaging Behav 10:1198-1205, 2016

16. Feng JT, Liu HQ, Xu JG, Gu YD, Shen YD: Differences in brain adaptive functional reorganization in right and left total brachial plexus injury patients. World Neurosurg 84:702708, 2015

17. Florence SL, Kaas JH: Large-scale reorganization at multiple levels of the somatosensory pathway follows therapeutic amputation of the hand in monkeys. J Neurosci 15:8083-8095, 1995

18. Flores LP: The radio-radial nerve transfer for elbow extension restoration in C5 to C7 nerve root injury. Microsurgery 32:55-59, 2012

19. Flores LP, Martins RS, Siqueira MG: Clinical results of transferring a motor branch of the tibial nerve to the deep peroneal nerve for treatment of foot drop. Neurosurgery 73:609-615, discussion 615-616, 2013

20. Flores LP, Socolovsky M: Phrenic nerve transfer for reconstruction of elbow extension in severe brachial plexus injuries. J Reconstr Microsurg 32:546-550, 2016

21. Foroni LHL: Anatomical Study of the Feasibility of Using the Intercostobrachial Nerve as a Donor in the Surgical Restoration of Hand Sensibility in Patients With Complete Brachial Plexus Injury [thesis]. São Paulo: Universidade de São Paulo, 2016

22. Fraiman D, Miranda MF, Erthal F, Buur PF, Elschot M, Souza L, et al: Reduced functional connectivity within the primary motor cortex of patients with brachial plexus injury. Neuroimage Clin 12:277-284, 2016

23. Fu SY, Gordon T: Contributing factors to poor functional recovery after delayed nerve repair: prolonged denervation. J Neurosci 15:3886-3895, 1995

24. Godefroy WP, Malessy MJA, Tromp AAM, van der Mey AGL: Intratemporal facial nerve transfer with direct coaptation to the hypoglossal nerve. Otol Neurotol 28:546-550, 2007

25. Gordon T, English AW: Strategies to promote peripheral nerve regeneration: electrical stimulation and/or exercise. Eur J Neurosci 43:336-350, 2016

26. Hayashi A, Nishida M, Seno H, Inoue M, Iwata H, Shirasawa T, et al: Hemihypoglossal nerve transfer for acute facial paralysis. J Neurosurg 118:160-166, 2013

27. Ho ES, Curtis CG, Clarke HM: Pain in children following microsurgical reconstruction for obstetrical brachial plexus palsy. J Hand Surg Am 40:1177-1183, 2015

28. House JW, Brackmann DE: Facial nerve grading system. Otolaryngol Head Neck Surg 93:146-147, 1985

29. Hua XY, Liu B, Qiu YQ, Tang WJ, Xu WD, Liu HQ, et al: Long-term ongoing cortical remodeling after contralateral C-7 nerve transfer. J Neurosurg 118:725-729, 2013

30. Irlbacher K, Meyer BU, Voss M, Brandt SA, Röricht S: Spatial reorganization of cortical motor output maps of stump muscles in human upper-limb amputees. Neurosci Lett 321:129-132, 2002

31. Jensen JL, Marstrand PC, Nielsen JB: Motor skill training and strength training are associated with different plastic changes in the central nervous system. J Appl Physiol (1985) 99:1558-1568, 2005

32. Kemp SW, Alant J, Walsh SK, Webb AA, Midha R: Behavioural and anatomical analysis of selective tibial nerve branch transfer to the deep peroneal nerve in the rat. Eur J Neurosci 31:1074-1090, 2010

33. Leechavengvongs $\mathrm{S}$, Witoonchart $\mathrm{K}$, Uerpairojkit $\mathrm{C}$, Thuvasethakul P: Nerve transfer to deltoid muscle using the nerve to the long head of the triceps, part II: a report of 7 cases. $\mathbf{J}$ Hand Surg Am 28:633-638, 2003

34. Li T, Hua XY, Zheng MX, Wang WW, Xu JG, Gu YD, et al: Different cerebral plasticity of intrinsic and extrinsic hand muscles after peripheral neurotization in a patient with brachial plexus injury: A TMS and fMRI study. Neurosci Lett 604:140-144, 2015

35. Lin JC, Schwentker-Colizza A, Curtis CG, Clarke HM: Final results of grafting versus neurolysis in obstetrical brachial plexus palsy. Plast Reconstr Surg 123:939-948, 2009

36. Liu Y, Lao J, Zhao X: Comparative study of phrenic and intercostal nerve transfers for elbow flexion after global brachial plexus injury. Injury 46:671-675, 2015

37. Lu Y, Liu H, Hua X, Xu WD, Xu JG, Gu YD: Supplementary motor cortical changes explored by resting-state functional connectivity in brachial plexus injury. World Neurosurg 88:300-305, 2016

38. Lu YC, Liu HQ, Hua XY, Shen YD, Xu WD, Xu JG, et al: Supplementary motor area deactivation impacts the recovery of hand function from severe peripheral nerve injury. Neural Regen Res 11:670-675, 2016

39. Lundborg G: Richard P. Bunge memorial lecture. Nerve injury and repair-a challenge to the plastic brain. J Peripher Nerv Syst 8:209-226, 2003

40. Lundborg G, Rosén B: Hand function after nerve repair. Acta Physiol (Oxf) 189:207-217, 2007

41. Mackinnon SE: Donor distal, recipient proximal and other personal perspectives on nerve transfers. Hand Clin 32:141151,2016

42. Malessy MJ, Hoffmann CF, Thomeer RT: Initial report on the limited value of hypoglossal nerve transfer to treat brachial plexus root avulsions. J Neurosurg 91:601-604, 1999

43. Malessy MJ, van Dijk JG, Thomeer RT: Respiration-related activity in the biceps brachii muscle after intercostal-musculocutaneous nerve transfer. Clin Neurol Neurosurg 95 (Suppl):S95-S102, 1993

44. Noaman HH, Shiha AE, Bahm J: Oberlin's ulnar nerve transfer to the biceps motor nerve in obstetric brachial plexus palsy: indications, and good and bad results. Microsurgery 24:182-187, 2004

45. Oberlin C, Béal D, Leechavengvongs S, Salon A, Dauge MC, Sarcy JJ: Nerve transfer to biceps muscle using a part of ulnar nerve for C5-C6 avulsion of the brachial plexus: anatomical study and report of four cases. J Hand Surg Am 19:232-237, 1994

46. Pondaag W, Malessy MJA: The evidence for nerve repair in obstetric brachial plexus palsy revisited. BioMed Res Int 2014:434619, 2014

47. Qiu TM, Chen L, Mao Y, Wu JS, Tang WJ, Hu SN, et al: Sensorimotor cortical changes assessed with resting-state fMRI following total brachial plexus root avulsion. J Neurol Neurosurg Psychiatry 85:99-105, 2014

48. Ray WZ, Murphy RK, Santosa K, Johnson PJ, Mackinnon SE: Medial pectoral nerve to axillary nerve neurotization following traumatic brachial plexus injuries: indications and clinical outcomes. Hand (NY) 7:59-65, 2012

49. Rochkind S, Shafi M, Alon M, Salame K, Fliss DM: Facial nerve reconstruction using a split hypoglossal nerve with preservation of tongue function. J Reconstr Microsurg 24:469-474, 2008

50. Rosén B, Björkman A, Lundborg G: Improved sensory relearning after nerve repair induced by selective temporary anaesthesia - a new concept in hand rehabilitation. J Hand Surg [Br] 31:126-132, 2006

51. Samardzic M, Grujicic D, Antunovic V: Nerve transfer in brachial plexus traction injuries. J Neurosurg 76:191-197, 1992

52. Samardzic M, Grujicic D, Rasulic L, Bacetic D: Transfer of the medial pectoral nerve: myth or reality? Neurosurgery 50:1277-1282, 2002

53. Simon NG, Franz CK, Gupta N, Alden T, Kliot M: Central adaptation following brachial plexus injury. World Neurosurg 85:325-332, 2016

54. Siqueira MG, Socolovsky M, Heise CO, Martins RS, Di Masi 
G: Efficacy and safety of Oberlin's procedure in the treatment of brachial plexus birth palsy. Neurosurgery 71:11561161,2012

55. Socolovsky M, Di Masi G, Battaglia D: Use of long autologous nerve grafts in brachial plexus reconstruction: factors that affect the outcome. Acta Neurochir (Wien) 153:22312240, 2011

56. Socolovsky M, di Masi G, Bonilla G, Domínguez Paez M, Robla J, Calvache Cabrera C: The phrenic nerve as a donor for brachial plexus injuries: is it safe and effective? Case series and literature analysis. Acta Neurochir (Wien) 157:1077-1086, 2015

57. Socolovsky M, Martins RS, di Masi G, Bonilla G, Siqueira M: Treatment of complete facial palsy in adults: comparative study between direct hemihypoglossal-facial neurorrhaphy, hemihipoglossal-facial neurorrhaphy with grafts, and masseter to facial nerve transfer. Acta Neurochir (Wien) 158:945957, 2016

58. Southwell DG, Hervey-Jumper SL, Perry DW, Berger MS: Intraoperative mapping during repeat awake craniotomy reveals the functional plasticity of adult cortex. J Neurosurg 124:1460-1469, 2016

59. Tse R, Kozin SH, Malessy MJ, Clarke HM: International Federation of Societies for Surgery of the Hand Committee report: the role of nerve transfers in the treatment of neonatal brachial plexus palsy. J Hand Surg Am 40:1246-1259, 2015

60. Tung TH, Mackinnon SE: Brachial plexus injuries. Clin Plast Surg 30:269-287, 2003

61. Wang SF, Li PC, Xue YH, Zou JY, Li WJ, Li Y: Direct coaptation of the phrenic nerve with the posterior division of the lower trunk to restore finger and elbow extension function in patients with total brachial plexus injuries. Neurosurgery 78:208-215, 2016

62. Witoonchart K, Leechavengvongs S, Uerpairojkit C, Thuvasethakul P, Wongnopsuwan V: Nerve transfer to deltoid muscle using the nerve to the long head of the triceps, part I: an anatomic feasibility study. J Hand Surg Am 28:628-632, 2003

63. Yang G, Chang KW, Chung KC: A systematic review of con- tralateral C7 transfer for the treatment of traumatic brachial plexus injury: part 1. Overall outcomes. Plast Reconstr Surg 136:794-809, 2015

64. Yang G, Chang KW, Chung KC: A systematic review of outcomes of contralateral C7 transfer for the treatment of traumatic brachial plexus injury: part 2. Donor-site morbidity. Plast Reconstr Surg 136:480e-489e, 2015

65. Yang TT, Gallen CC, Ramachandran VS, Cobb S, Schwartz BJ, Bloom FE: Noninvasive detection of cerebral plasticity in adult human somatosensory cortex. Neuroreport 5:701-704, 1994

66. Yoshikawa T, Hayashi N, Tajiri Y, Satake Y, Ohtomo K: Brain reorganization in patients with brachial plexus injury: a longitudinal functional MRI study. Sci World J 2012:501751, 2012

67. Zheng MX, Xu WD, Qiu YQ, Xu JG, Gu YD: Phrenic nerve transfer for elbow flexion and intercostal nerve transfer for elbow extension. J Hand Surg Am 35:1304-1309, 2010

\section{Disclosures}

The authors report no conflicts of interest concerning the materials or methods used in this study or the findings specified in this paper.

\section{Author Contributions}

Conception and design: Socolovsky, Lopez, Flores. Acquisition of data: Socolovsky, Malessy, Lopez, Guedes. Analysis and interpretation of data: all authors. Drafting the article: Socolovsky, Malessy, Guedes, Flores. Critically revising the article: Malessy, Guedes, Flores. Reviewed submitted version of manuscript: Socolovsky, Malessy, Lopez, Flores. Approved the final version of the manuscript on behalf of all authors: Socolovsky.

\section{Correspondence}

Mariano Socolovsky, La Pampa 1175 Torre 2 5A, Buenos Aires 1428, Argentina. email: marianosocolovsky@gmail.com. 